\title{
Checklist: A key to safety
}

\author{
Harpreet Kaur' ${ }^{1}$, Veena Shukla ${ }^{2, *}$, Ranjana Khetarpal ${ }^{3}$, Magila Muthuramalinga Pandian ${ }^{4}$ \\ ${ }^{1}$ Professor, ${ }^{2}$ Senior Specialist, Dept. of Anaesthesia, SMS Medical College, Jaipur, Rajasthan, ${ }^{3}$ Professor, Dept. of Anaesthesia, \\ Government Medical College, Amritsar, Punjab, ${ }^{4}$ Consultant Anaesthesia, Dept. of Anaesthesia, Gem Hospital and Research \\ Centre, Coimbatore, Tamil Nadu, India
}

*Corresponding Author:

Email: drshuklaveena@gmail.com

Received: $9^{\text {th }}$ April, 2018

Accepted: $13^{\text {th }}$ May, 2018

\begin{abstract}
Modern medicine involves highly specific and sophisticated techniques and equipments. However, human errors as well as equipment failure may lead to fatal accidents an increase in the cost of health care. Using checklist as tool for surgical safety involves safe anaesthesia, maintenance of open airway, correct surgical site, infection control and efficient communications and team work. Although no checklist is universal or guarantees absolute safety, an effective checklist has a patient centered approach and keeps patient safety and comfort a priority.
\end{abstract}

Keywords: Checklist, Patient safety, Health care, Anaesthesia equipment.

\section{Introduction}

Technical advancements in the ever changing field of medicine has led to dependence on various hi-tech equipments. Still none of them are fool proof and chances of equipment failure and manual errors can not be ruled out. Thus, the need to improve the quality of healthcare system is obvious while understanding of complex relations amongst its components, which are the, human resources, the technical resources, and their interactions. ${ }^{1}$

In the present scenario mortality and morbidity in hospital grabs headlines in media putting the concerned clinician at the receiving end. Thus, the need to double check the safety mechanism arises to ensure safety of the patient as well as medical personnel. Data for this review article was collected through PubMED ${ }^{\circledR}$, MEDLINE $^{\circledR}$, Google Scholar and HHS Public Access.

Anaesthesia Safety in Modern Times: Last 20 years have seen major improvements in patient's safety in the field of anaesthesia owing to continuous and organized effort. ${ }^{2}$ The mortality rates have reduced from 2 per 10,000 to 1 per $3,00,000 .^{3}$

Routinely employed methods to enhance safety in anaesthesia include simulation, training and encouraging team work, reporting of critical incidents and training to use safety systems. ${ }^{4-7}$

In spite of all the improvements, challenge that remains with us is ensuring safety of patients having serious co-morbidities. ${ }^{8}$

Cooper and Gaba et al have analyzed that though anaesthesia related mortalities have decreased in healthy patients, it is still higher than desired for all surgical cases in totality, which may plateau or decrease in case further improvements are not made. ${ }^{9}$

Reported frequency of anaesthesia equipment failure is about $0.04 \%$ to $0.23 \%$ out of which two -thirds are due to malfunction of anaesthesia machines while one-thirds is due to human errors. ${ }^{10-11}$

Anaesthsia Checklist- A Tool for Surgical Safety: Using checklists as tools for surgical safety involve components like safe anaesthesia and maintenance of an open airway, correct site of surgery, infection control and efficient communication and teamwork. ${ }^{12-19}$

According to surveys by World Health Organization (WHO), 321 million surgical procedures are being performed throughout the world annually, with $10 \%$ incidence of adverse events in the hospital. Majority of these are related to the surgery, with $0.4-0.8 \%$ death rate and $3-17 \%$ major complications rate in developed countries. Half among them are preventable. ${ }^{20-23}$

WHO, in 2008 developed Safe Surgery Saves Lives guidelines, which consisted of 22 items.

The perioperative times considered critical by the checklist include induction of anaesthesia, incision, and time before shifting the patient out of operating room.

'Sign- in' before induction is meant to confirm identity of the patient, surgical site and name of procedure. Checking of anaesthesia machine and drugs, presence of pulse oximeter, checking for any allergies, risk of difficult airway and aspiration or excessive blood loss are all part of 'sign -in'.

'Time- out' which is the time prior to skin incision, involves identifying members of the team by names and roles, checking name of the patient, surgery to be performed, whether prophylactic dose of antibiotic has been given an hour before, displaying of the important images, estimating length of surgery and the blood loss.

'Sign- out' time before shifting the patient out of operating room, includes counting the instruments, needles and sponges, labeling the surgical specimens and discussing postoperative management issues. ${ }^{24}$

Heynes et al published their first multicentric evaluation of WHO surgical safety checklist in 2009, in 
which they selected 8 centers in 8 countries with a total of 7688 patients. They implemented WHO safety checklist in 3955 patients out of total. They observed complications and death rates, pre and post implementation of the checklist. The overall drop in complication rate was from $11 \%$ to $7 \%(\mathrm{p}<0.001)$ and of mortality from $1.5 \%$ to $0.8 \%(\mathrm{p}=0.003)$. Surgical site infection and unplanned reoperation also reduced significantly $(\mathrm{p}<0.001$ and $\mathrm{p}=0.047$ respectively).They stated that implementation of checklist also improved the adherence rate of antibiotic prophylaxis from $56 \%$ to $83 \%$, thus lowering the surgical site infection. ${ }^{25}$

Also Hawthorne effect, that is improvement in performance of people when they are aware of being observed also could be one of the factors. ${ }^{26}$

Similarly, other researches also quoted in their multicentric meta analysis that checklist helped to reduce complications, surgical site infection and mortality following its implementation. ${ }^{27}$

In a recent study conducted in 2017 , the authors observed a reduction in post surgery deaths by $22 \%$ after use of WHO surgical safety checklist. ${ }^{28}$

Another recent study (2017) conducted in the context of validation of pre and post operative WHO Safe Surgery Saves Lives checklist concluded that checklist is a useful tool for initiating preventive strategies along with monitoring of warning signs of complications, planning at initial stage and improving communication amongst the surgical team. All these benefits ultimately enhance the patient safety. ${ }^{29}$

However, studies conducted in 2012 showed that compliance with safety checklist has been low even after its implementation benefits. Various other subsequent studies also quoted similar results. ${ }^{30-33}$

A study conducted on plastic surgery patients showed no significant reduction in complications or mortality. ${ }^{34}$

Checklist -A Communication Tool: In a study by Pugel et al in 2015, authors have found that WHO surgical safety checklist reduced complications by improving communication among team member's surgeons, anaesthesiologists and nursing staff. They have emphasized the use of WHO checklist as a communication tool. ${ }^{35}$

According to various studies, communication failures are common in operating rooms, which occur every 7-8 minutes and affect $30 \%$ of the interactions. ${ }^{36-}$ 37

Use of checklist is beneficial in preventing around half of the communication gaps. ${ }^{38}$

A study also stated that briefing at the start of procedure reduces two third of communication failures. ${ }^{39}$ Briefing also has been shown to improved team work and output of the providers. ${ }^{40}$

However, monitoring compliance of checklist is important after its implementation. ${ }^{41}$ Authors have also stated that a system of feedback from the providers regarding patient outcomes and adjustments in checklist to suit the local needs of the team may help to improve the compliance and adherence. ${ }^{42-43}$

Recent meta analysis by Law et al in 2016 included results of ten studies involving 51,125 patients with 27,490 pre-implementation and 23,635 post implementation cases of WHO safety checklist. They observed a significant decline in total complications $(37.9 \%)$, unplanned re-surgery $(32.1 \%)$, surgical site infection $(45.5 \%)$, and mortality $(15.3 \%)$.

Various other parameters like airway evaluation, use of pulse oximeter, confirmation of patient name and surgical site, use of profile active anti-biotic and counting of sponges also improved. They concluded that WHO safety checklist is a valuable tool to be used globally in all surgical centers. ${ }^{24}$

American Society of Anaesthesiologists PreAnaesthesia Check out: American society of anaesthesiologists (ASA) task force developed guidelines for pre anaesthesia check out procedures for checking of equipments in 1993, which were upgraded in 2008. These guidelines are helpful to design individual checklists in accordance with individual anaesthesia machines design and requirements.

In addition, these guidelines recommend the involvement of technical staff in the operating theater for checkout procedure of anaesthesia machine and equipments. However, the anaesthesia care provider is responsible ultimately for the proper functioning of anaesthesia equipment. ${ }^{44}$

According to ASA guidelines basic equipment for safe anaesthesia delivery include, reliable oxygen delivery at any concentration up to $100 \%$, reliable source of positive pressure ventilation as well as back up ventilation facilities, breathing circuits providing controlled release of positive pressure, delivery of anaesthesia vapours, presence of working suction and adequate patient monitoring. In addition, documentation of completing the checkout procedure is also mandatory. ${ }^{45-46}$

World Federation of Society of Anaesthesiologists (WFSA)- International Standards: WFSA adopted safety standards in 1992 and updated them in 2008 and 2010.

The standards laid down in making of safety checklist or international standards of safe anaesthesia practice in 2010 are international recommendations to guide and help the anaesthesiologists to maintain and improve the standards of care.

Mandatory standards of providing anaesthesia for elective surgeries have to be met at any cost. Only urgent life-saving or limb saving emergencies can be permitted at standards below the mandatory in some centers, where mandatory standards should be maintained at the earliest.

The minimum standards worldwide for elective procedures, which are mandatory, are termed as highly recommended. These minimum standards are acceptable in settings where resources are very limited and the procedure is necessary. These resources are also called 
as level 1 or basic infrastructure. Level 2 or recommended standards are intermediate level and level 3 or suggested standards are the optimal level of standards to be achieved in any operation setup.

WFSA has adopted these standards based on essential components like hospital infra structure, procedure to be performed, personnel involved, drugs and equipments available. These standards include pre anaesthetic check up of patient as well as checking of equipments and drugs in accordance with WHO checklist.

Monitoring during anaesthesia standards include uninterrupted oxygen supply and patient oxygenation, monitoring of adequate airway and ventilation, circulation and tissue perfusion, temperature monitoring, monitoring of neuromuscular function and depth of anaesthesia as well as the available alarm with set limit values.

Post anaesthesia care standards check for post anaesthesia recovery location, monitoring, and pain relief. ${ }^{47}$

Association of Anaesthesiologists of Great Britain and Ireland (AAGBI)_Checklist for Anaesthesia Equipment: AAGBI developed anaesthesia equipment safety checklists in 1997, 2004 and 2012. This checklist recommends using machine self-test procedures along with AAGBI checklist to ensure safety as well as emphasis its documentation. This checklist is divided into various sections according to the parts of machine and equipment to be checked. ${ }^{48}$

Value of Checklist in Post Anaesthesia Hand over of Patient: According to authors, transfer of responsibility of patient care by one professional to another temporarily or permanently is known as patient handover. ${ }^{49}$ However; patient care can be affected by lack of proper transfer of information during handover. ${ }^{49-50}$

Various organizations and personnel have recommended standardized handover procedure in recovery rooms to ensure patient safety. ${ }^{51-52}$

Studies have shown that handovers in medical specialties are brief and informal. ${ }^{50-57}$ and handover of information regarding patients is rare in the specialty of anaesthesia. ${ }^{52,58,59}$

In a recent study by Salzwedel et al, authors developed a comprehensive checklist for post anaesthesia handover of elective surgery patients by anaesthesiologist to the post anaesthesia care unit (PACU) nurse. They observed that use of checklist improved the number of items regarding patient's information in PACU from $32.4 \%$ before the use of checklist to $48.7 \%$ after its use. Also, the duration of handover hiked from 86 seconds to 121 seconds. They concluded that use of checklist might improve quality of patient's handover in immediate post anesthesia period. ${ }^{60}$

Authors in other studies have quoted similar results. ${ }^{61,62}$
Perception of Anaesthesiologists on use of Checklists: Krombach et al carried out a survey on the perception of anaesthesia providers regarding use of checklist and other cognitive aids using a questionnaire. They were asked to give their opinion about use of checklist in routine and emergency situations.

Authors observed that $98 \%$ of respondents considered time out or the pre- incision time checklist to be important or very important. In addition, 87-97\% preferred using checklist during time of crisis.

$54 \%$ of the least and $50 \%$ of the most experienced personnel valued the use of checklist in routine anaesthesia care. Only $29 \%$ anaesthesia providers with 2-10 yrs experience were interested to use checklist.

The reasons given for not using checklist routinely were distraction from patient care in $27 \%$ and lower efficiency in $31 \%$ of this group.

The authors concluded that the survey documents the importance of human errors and that the integration of checklist in the routine clinical usage could lead to successful implementation of these aids and tools. ${ }^{63}$

In a previous study in this regard, the authors had stated that $95 \%$ of participants found pre -induction checklist useful and $80 \%$ were interested to use checklist further during simulation trainings. However, only $40 \%$ participants wanted to use checklist in routine practice. ${ }^{64}$

\section{Conclusion}

The checklist is much more than just a list of checks. It includes the things or procedures, which should be done for every patient every time.

A structured initiative to get all organizations/ hospitals to use the safety checklist is need of hour. Effective and efficient performance of the safety actions and communication are the key to improve safety.

No checklist is universal and its implementation cannot guarantee safety. These are effective only with the patient centered approach keeping safety and comfort on the top of agenda.

\section{References}

1. Bajaj P. What's New in Patient Safety and How It Will Affect Your Practice. I J A. 2007;51(5):363-364.

2. Silber JH, Kennedy SK, Even-Shoshan O. Anesthesiologist direction and patient outcomes. Anesthesiology. 2000;93:152-63.

3. Beckman U, West L, Groombridge G. The Australian incident monitoring study in intensive care: AIMS-ICU. The development and evaluation of a voluntary anonymous incident reporting system. Anesth Intensive Care. 1996;24:315-26.

4. Baker D, Gustafson S, Beaubien J. Medical teamwork and patient safety: the evidence-based relation.2005. AHRQ PublicationNo.05-0053.

5. Gaba DM, Howard SK, Fish KJ. Simulation-based training in anesthesia crisis resource management (ACRM): a decade of experience. Simulat Gaming. 2001;32:175-93.

6. Morray JP, Geiduschek JM, Ramamoorthy C. Anesthesia related cardiac arrest in children: initial findings of the 
pediatric peri-operative cardiac arrest registry (POCA). Anesthesiology. 2000;93:6-14.

7. Reason J. Managing the risks of organizational accidents. Aldershot, UK: Ashgate, 1997.

8. Lagasse RS. Anesthesia safety: model or myth? Anesthesiology. 2002;97:1609-17.

9. Cooper J, Gaba D. No myth: anesthesia is a model for addressing patient safety. Anesthesiology. 2002;97:13357.

10. Fasting S, Gisvold S.E. Equipment problems during anaesthesia-are they a quality problem? $\mathrm{Br} \mathrm{J}$ Anaesth. 2002;89:825-831.

11. Klanarong S, Chau-in, W, Pulnitiporn A., Pengpol W. The Thai Anesthesia Incidents Study (THAI Study) of anesthetic equipment failure/malfunction: a qualitative analysis for risk factors. $J$ Med Assoc

Thai. 2005;88:S134-140.

12. Pronovost, PJ, Goeschel, CA, Marsteller, JA, Sexton, JB, Pham, JC, Berenholtz, SM Framework for patient safety research and improvement Circulation. 2009;119: 330-7

13. Weiser TG, Berry WR. Review article: Perioperative checklist methodologies. Can J Anaesth. 2013;60:13642.

14. Makary MA, Holzmueller CG, Thompson D, Rowen L, Heitmiller ES, Maley WR, Black JH, Stegner K, Freischlag JA, Ulatowski JA, Pronovost PJ.Operating room briefings:Working on the same page. Jt Comm J Qual Patient Saf. 2006;32:351-5.

15. Lingard L, Espin S, Rubin B, Whyte S, Colmenares M, Baker GR, Doran D, Grober E, Orser B, Bohnen J, Reznick R. Getting teams to talk: Development and pilot implementation of a checklist to promote inter professional communication in the OR. Qual Saf Health Care. 2005;14:340-6.

16. Bleakley A, Boyden J, Hobbs A, Walsh L, Allard J. Improving teamwork climate in operating theatres: The shift from multiprofessionalism to interprofessionalism. $J$ Interprof Care. 2006;20:461-70.

17. Lingard L, Regehr G, Cartmill C, Orser B, Espin S, Bohnen J, Reznick R, Baker R, Rotstein L, Doran D. Evaluation of a preoperative team briefing: A new communication routine results in improved clinical practice. BMJ Qual Saf. 2011;20:475-82.

18. Makary MA, Sexton JB, Freischlag JA, Holzmueller CG, Millman EA, Rowen L, Pronovost PJ. Operating room teamwork among physicians and nurses: Teamwork in the eye of the beholder. J Am Coll Surg. 2006;202:74652.

19. Gillespie BM, Chaboyer W, Longbottom P, Wallis M. The impact of organizational and individual factors on team communication in surgery: A qualitative study. Int $J$ Nurs Stud. 2010;47:732-41.

20. Rose J, Weiser T.G., Hider P., Wilson L., Gruen R.L. and Bickler S.W. (2015) Estimated Need for Surgery Worldwide Based on Prevalence of Diseases: A Modelling Strategy for the WHO Global Health Estimate. The Lancet Global Health. 3, S13-S20.

21. Weiser T.G., Regenbogen S.E., Thompson K.D., Haynes A.B., Lipsitz S.R., Berry W.R., et al. (2008) An Estimation of the Global Volume of Surgery: A Modeling Strategy Based on Available Data. Lancet. 372:139-144.

22. (2009) WHO Guidelines for Safe Surgery 2009: Safe Surgery Saves Lives. World Health Organization, Geneva.

40. Makary MA, Mukherjee A, Sexton J.B, Syin D, Goodrich E, Hartmann E, et al. Operating room briefings and wrong-site surgery. J Am Coll Surg. 2007;204:236-243.
23. Kable AK, Gibberd RW, Spigelman AD. Adverse events in surgical patients in Australia. Int J Qual Health Care. 2002;14:269-276.

24. Lau C.S.M. and Chamberlain R.S. (2016). The World Health Organization Surgical Safety Checklist Improves Post-Operative Outcomes: A Meta-Analysis and Systematic Review. Surgical Science. 2016;7:206-217.

25. Haynes AB, Weiser TG, Berry WR, Merry AF, Moorthy $\mathrm{K}$, Gawande AA, et al. A surgical safety checklist to reduce morbidity and mortality in a global population. $N$ Engl J Med. 2009;360:491-499.

26. Mayo E. The human problems of an industrial civilization. New York: Macmillan, 1933.

27. Bergs J, Hellings J, Cleemput I, Zurel O, De Troyer V, Van Hiel M, et al. (2014) Systematic Review and MetaAnalysis of the Effect of the World Health Organization Surgical Safety Checklist on Postoperative Complications. British Journal of Surgery. 101:150-158.

28. Mc.Carthy M, WHO surgical safety checklist cuts post surgical deaths by $22 \%$, US study finds. $B M J$. 2017;357:j;1935.

29. Alpendre FT, Cruz EDA, Dyniewicz AM, et al. (2017) Safe Surgery: Validation of Pre and Post Operative Checklists. Rev Lat Am. Enfermagem.2017;10;25:e2907.

30. Levy SM, Senter CE, Hawkins RB, Zhao JY, Doody K., Kao L.S, et al. (2012) Implementing a Surgical Checklist: More than Checking a Box. Surgery. 2012;52:331-336.

31. Fourcade A, Blache JL, Grenier C, Bourgain JL, Minvielle E. (2012) Barriers to Staff Adoption of a Surgical Safety Checklist. BMJ Quality and Safety. 2012;21:191-197.

32. Saturno PJ, Soria-Aledo V, Da Silva Gama ZA, LorcaParra F and Grau-Polan, M. (2014) Understanding WHO Surgical Checklist Implementation: Tricks and Pitfalls. An Observational Study. World Journal of Surgery. 2014;38:287-295.

33. Bashford T, Reshamwalla S, McAuley J, Allen NH, McNatt Z and Gebremedhen,YD. (2014) Implementation of the WHO Surgical Safety Checklist in an Ethiopian Referral Hospital. Patient Safety in Surgery; 2014;8:16.

34. Biskup N, Workman A.D, Kutzner E, Adetayo O.A. and Gupta S.C. (2015) Perioperative Safety in Plastic Surgery: Is the World Health Organization Checklist Useful in a Broad Practice? Annals of Plastic Surgery. 72015;6:550-555.

35. Pugel AE, Simianu VV, Flum DR, Dellinger EP. Use of the Surgical Safety Checklist to Improve Communication and Reduce Complications. Journal of infection and public health. 2015;8(3):219-225.

36. Hu YY, Arriaga AF, Peyre SE, Corso KA, Roth EM, Greenberg CC. Deconstructing intraoperative communication failures. J Surg Res. 2012;177(1):37-42.

37. Lingard L, Espin S, Whyte S, Regehr G, Baker G.R, Reznick R. et al, Communication failures in the operating room: an observational classification of recurrent types and effects. Qual Saf Health Care. 2004;13:330-334.

38. Henrickson SE, Wadhera RK, Elbardissi AW, Wiegmann DA, Sundt TM. 3rd. Development and pilot evaluation of a preoperative briefing protocol for cardiovascular surgery. J Am Coll Surg. 2009;208:1115-1123.

39. Lingard, L., Regehr, G., Orser, B., Reznick, R., Baker, G.R., Doran, D. et al, Evaluation of a preoperative checklist and team briefing among surgeons, nurses, and anesthesiologists to reduce failures in communication. Arch Surg. 2008;143(1):12.

41. Rydenfalt C, Johansson G, Odenrick P, Akerman K., Larsson PA. Compliance with the WHO surgical safety 
checklist: deviations and possible improvements. Int $J$ Qual Health Care. 2013;25:182-187.

42. Russ, S.J., Sevdalis, N., Moorthy, K., Mayer, E.K., Rout, S., Caris, J. et al, A qualitative evaluation of the barriers and facilitators toward implementation of the WHO surgical safety checklist across hospitals in England. Ann Surg. 2015;261:81-91.

43. Putnam, L.R., Levy, S.M., Sajid, M., Dubuisson, D.A., Rogers, N.B., Kao, L.S. et al, Multifaceted interventions improve adherence to the surgical checklist. Surgery. 2014;156:336-344.

44. Recommendation for Pre Anesthesia Checkout Procedures (2008). Available at :http://www.asahq.org/clinical/fda.htm (last accessed on 23March2018)

45. American Society of Anesthesiologists. Standards for Basic Anesthetic Monitoring. Oct25,2005. http://www.asahq.org/publication And Services/standards/02.pdf.(last accessed on 23March2018)

46. Scope and Standards for Nurse Anesthesia Practice, in the Professional Practice Manual for the Certified Registered Nurse Anesthetist (2006), American Association of Nurse Anesthetists, Park Ridge, IL.

47. Merry AF, Cooper JB, Soyannwo O, Wilson IH, Eichhorn JH. International Standards for a Safe Practice of Anesthesia 2010. Canadian Journal of Anaesthesia. 2010;57(11):1027-103.

48. Magee P. Checking anaesthetic equipment: AAGBI 2012 guidelines. Anesthesia. 2012;67:571-574.

49. BMA junior doctors committee — safe handover: safe patients 2004. http:// www.bma.org.uk/image/safe handover_tcm41-20983.pdf (last accessed on 23March2018)

50. Catchpole K, Sellers R, Goldman A. Patient handovers within the hospital: translating knowledge from motor racing to healthcare. Qual Saf Health Care. 2010;19:31822

51. Cohen MD, Hilligoss PB. The published literature on handoffs in hospitals: deficiencies identified in an extensive review. Qual Saf Health Care. 2010;19:493-7.

52. Wong MC, Turner P, Yee KC. Socio-Cultural issues and patient safety: a case study into the development of an electronic support tool for clinical handover. Stud Health Technol Inform. 2007;130:279-89

53. Horn J, Bell MD, Moss E. Handover of responsibility for the anaesthetised patient-opinion and practice. Anaesthesia. 2004;59:658-63.
54. Nagpal K, Arora S, Abboudi M. Postoperative handover. Ann Surg. 2010;252:171-6.

55. Bomba DT, Prakash R. A description of handover processes in an Australian public hospital. Aust Health Rev. 2005;29:68-79.

56. Alvarado K, Lee R, Christoffersen E, et al. Transfer of accountability: transforming shift handover to enhance patient safety, Healthc Q. 2006;9:75-9.

57. McFertridge B, Gisllespie M, Goode D. An exploration of the handover process of critically ill patients between nursing staff from the emergency department and the intensive care unit. Nurs Crit Care. 2007;12:261-9.

58. Sabir N, Yentis SM, Holdcroft A. A national survey of obstetric anaesthetic handovers. Anaesthesia. 2006;61:376-80

59. Smith AF, PopeC, Goodwin D et al. Interprofessional handover and patient safety in anaesthesia: observational study of handovers in the recovery room. Br J Anaesth. 2008;101:332-7.

60. Salzwedel C, Bartz HJ, Kühnelt I, Appel D, Haupt O, Maisch S, Schmidt GN. The effect of a checklist on the quality of post-anaesthesia patient handover: a randomized controlled trial. International Journal for Quality in Health Care. 2013;pp.1-6.

61. Catchpole KR, de Leval MR, McEwan A, et al. Patient handover from surgery to intensive care: using Formula 1 pit-stop and aviation models to improve safety and quality. Paediatr Anaesth. 2007;17:470-8

62. Ferran NA, Metcalfe AJ, O' Doherty D. Standardised proformas improve patient handover: audit of trauma handover practice. Patient Saf Surg. 2008;2:24.

63. Krombach JW, Edwards WA, Marks JD, Radke OC. Checklists and Other Cognitive Aids For Emergency And Routine Anesthesia Care-A Survey on the Perception of Anesthesia Providers From a Large Academic US Institution. Anesthesiology and Pain Medicine. 2015;5(4).

64. Hart EM, Owen H. Errors and omissions in anesthesia: a pilot study using a pilot's checklist. Anesth Analg. 2005;101(1):246-50.

How to cite this article: Kaur $\mathrm{H}$, Shukla V, Khetarpal R, Pandian MM. Checklist: A key to safety. Indian J Clin Anaesth. 2018;5(3):306-310. 